\title{
Will organic sake intoxicate consumers? Procurements of rice as bottlenecks and comparative procurement strategies by four brewers in Japan
}

\author{
Yoshitaka Miyake(D) and Ryo Kohsaka* (D)
}

\begin{abstract}
This study reviews the status of current organic sake and procurement strategies of organic rice by four brewers in Japan. Despite overall declining trends in shrinking domestic markets, sake categorized in the premium segment has been increasing in trading volumes and indicated resilience in prices.

This study first reviewed and analyzed the overall status of sake, trends in premium segment, and challenges for organic sake. Unlike wine, organic sake occupies a minor position in the segment. This was followed by the comparative analysis of procurement strategies of organic rice for four sake breweries in Japan. The strategies were contrasting; three breweries indicated strong "local" bonding while one procured organic rice outside of the region, resulting in different product strategies. At its initiation, all four breweries showed the interests in local agriculture and gained rice locally. Then, availability and affordable price became a bottleneck. Implications of these challenges are further analyzed from exporting perspectives as well.
\end{abstract}

Keywords: Organic agriculture, Export, Local development, Terroir, Rice, Sake, Japan

\section{Introduction}

Sake has been part of Japanese culture from the ancient time as the national foundation mythologies of Kojiki and Nihonshoki described them [1]. Brewing at low temperature developed at the time of the Song Dynasty of China (960-1279). Japan accepted this technology around 1570 . In addition, the technologies have been developing to overcome immature flavors. First is the development of malt. Malt production became stable in the Muromachi period (1336-1573). The recipe of malt was shared among select groups. Malt became spread in the Meiji period (1868-1912). In the same period, scientists started to be involved in the studies of malt. In recent years, malt became specified to types of the products. Second, the scientific separations of yeasts

\footnotetext{
* Correspondence: kohsaka@hotmail.com

Graduate School of Environmental Studies, Nagoya University, Furo-Cho Chikusa-Ku, Nagoya City, Aichi 464-8601, Japan
}

started in the late ninetieth century. Amongst historical yeast, the "Number 6 yeast" is still used in brewing which was originally separated from a brewery in Akita Prefecture in 1930 [2]. After the WWII, the development of yeasts rapidly contributed to the evolution to the current flavor of sake [1]. Nowadays, the breweries polish the rice surface and have the scent given off from premium sake.

The overall production of sake has been decreasing in contemporary Japan mainly due to diversification of preferences particularly for younger generations and decreasing population. In short, the domestic market, the production volume more than halved in the last 20 years. Despite such decline, the demand on premium sake and the increase of the export were relatively strong to provide positive prospects on the industry.

The production of sake in Japan has been decreasing from the perspective of volumes. While it was 1133

(c) The Author(s). 2020 Open Access This article is licensed under a Creative Commons Attribution 4.0 International License, which permits use, sharing, adaptation, distribution and reproduction in any medium or format, as long as you give

appropriate credit to the original author(s) and the source, provide a link to the Creative Commons licence, and indicate if changes were made. The images or other third party material in this article are included in the article's Creative Commons licence, unless indicated otherwise in a credit line to the material. If material is not included in the article's Creative Commons licence and your intended use is not permitted by statutory regulation or exceeds the permitted use, you will need to obtain permission directly from the copyright holder. To view a copy of this licence, visit http://creativecommons.org/licenses/by/4.0/ 


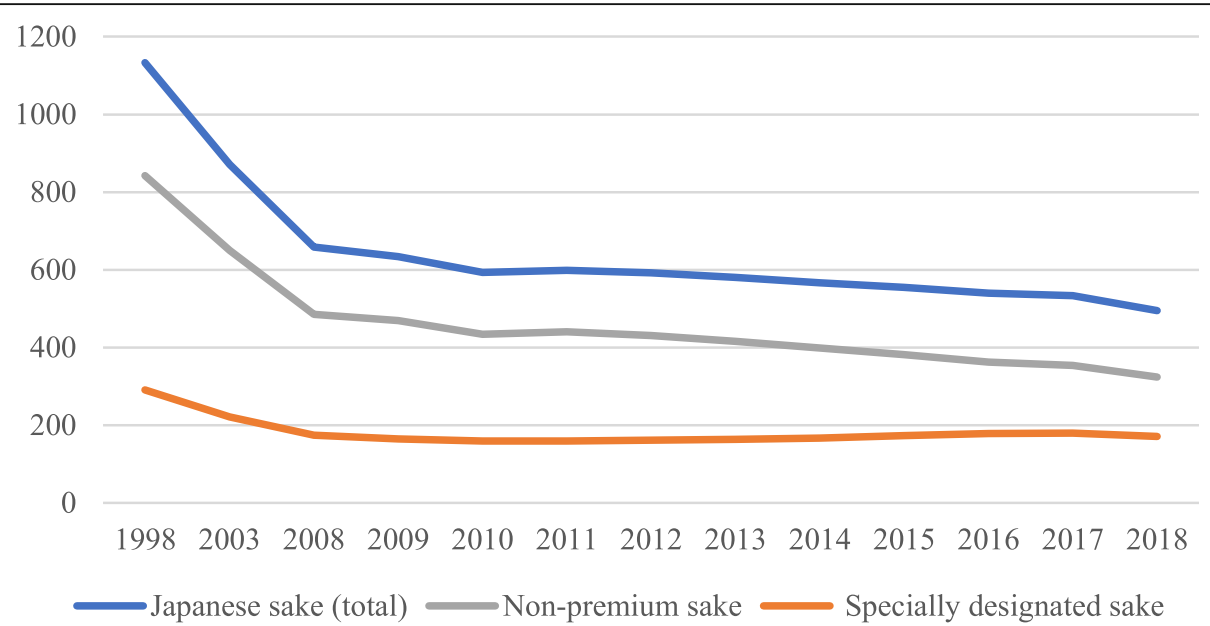

Fig. 1 Shipment of Japanese sake (million liters). The trend of the overall production of sake has declined. The trend is attributed to the decline of the production of non-premium sake. The production of specifically designated sake, premium sake, increased from 2012 to 2017 . The sale after the East-Japan earthquake and tsunami could contribute to this increase as the consumers notice the quality of premium sake [3]. Modified from [4]

Table 1 The labeling standard of sake by production quality. Tax Agency decides the sake categories in Japan as below. Sake is at first categorized into specially designated sake and non-premium sake. Specially designated sake is then categorized into pure-rice sake type and honjōzō-shu kei. These categories are based on the ingredients such as edible ethanol. Furthermore, both pure-rice sake type and honjōzō-shu kei are classified by rice-polishing ratio. Rice polishing reduces the coarse flavors related to the acids [1]

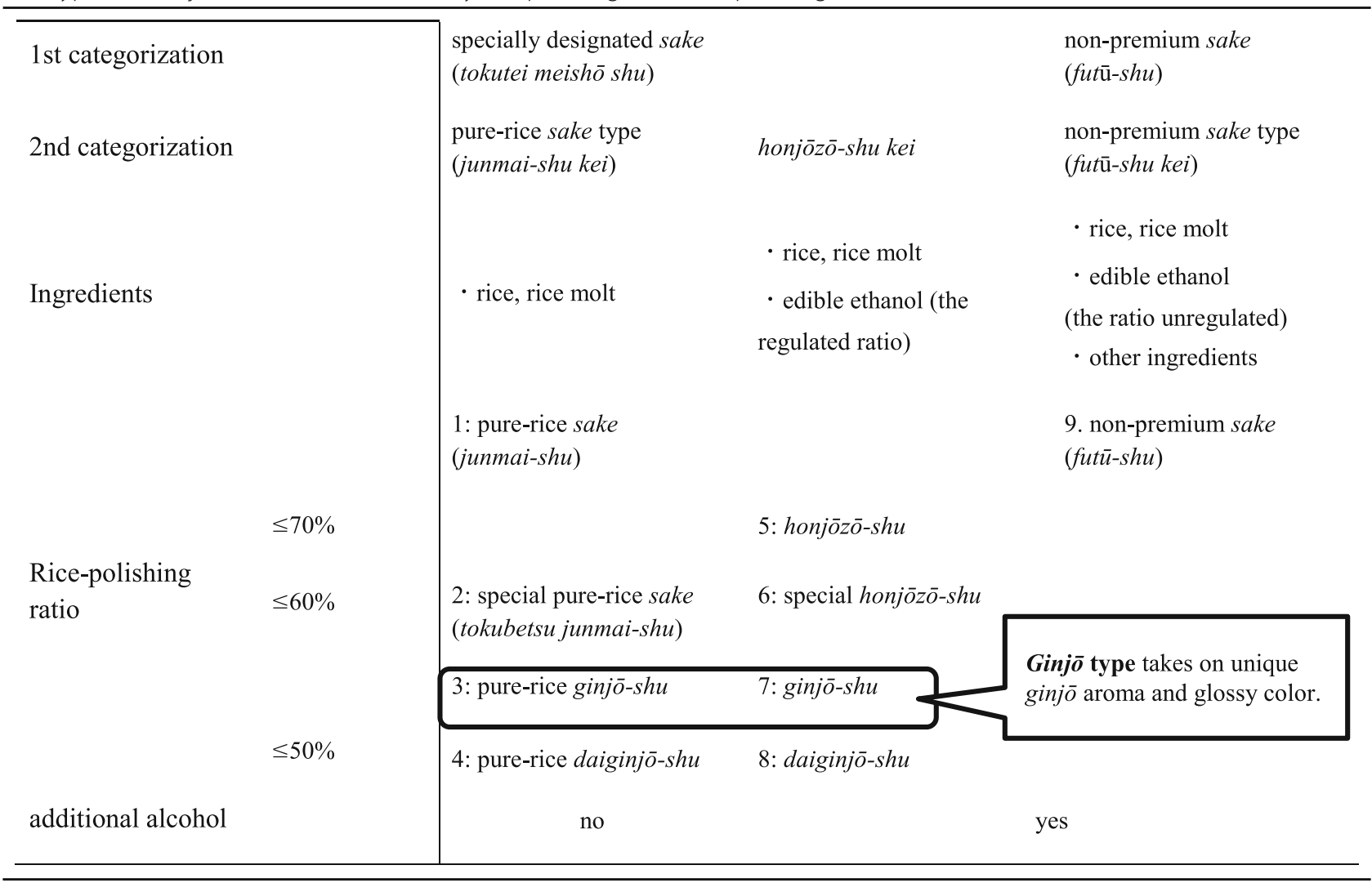


million liters in 1998, it is currently 495 million liters in 2018 (Fig. 1). The decrease is attributed to the shift of consumer preference and aging population [4]. In contemporary era, sake has to compete with other alcohol drinks such as liquors, shochu (Japanese distilled liquors of buckwheat, wheat, and sweet potatoes), and wine.

Despite such overall decline of alcohol or sake production, the production of specially designated sake (tokutei meishō shu), premium sake, is rather strong (Table 1). This reflects the consumer preference for high-quality luxurious goods with terroir, or local and environmental stories [3]. Additionally, the increase of the export underlies the demand on luxurious sake (Fig. 2). In 2018, the export accounted for $4.9 \%$ of the total sake shipment in Japan [4]. The Japanese government deregulated Liquor Tax Law in 2020 in order to boost the exports [5]. Production permits were previously under strict controlled in numbers but will be deregulated and granted additionally for products exclusively for exports.

Such increase of demands on high-quality sake did not accompany the increase of sake-brewing rice in corresponding way (Fig. 3). The production of sake-brewing rice halted its increase in 2015. As the price of sakebrewing rice is much higher than that of conventional edible rice, the production of sake-brewing rice increased to cause the overproduction in the year with good rice harvest [4]. Still, sake-brewing rice continues to be more expensive; for example, in 2018, compared with 14,524 yen $/ 60 \mathrm{~kg}$ for conventional edible rice at a farm gate, the price of sake-brewing Yamadanishiki variety in Hyōgo Prefecture was 23,600 yen, and Gohyakumangoku in Niigata Prefecture costed 16,100 yen [4]. Furthermore, the price decrease of conventional edible rice keeps sake-brewing rice attractive to produce [7]. When Japan accepted the Uruguay Round agreement in 1994, the farm-gate price of conventional edible rice was 21,364 yen $/ 60 \mathrm{~kg}$ [8]. In recent period from 2014 to 2018 , the prices were the lowest at 11,967 yen in 2014 and the highest at 15,695 yen in 2018 [9]. To stabilize the market of sake-brewing rice, Ministry of Agriculture, Forestry, and Fisheries (MAFF) recommended the farmers be sensitive to the market information [4]. Similarly, could the introduction of another sake category of organic sake help stabilize the production of sake and sake-brewing rice? What does it mean for exporting makers?

In the existing studies, there was a range of analysis [1, 10-12]. For example, Sato and Kohsaka (2017) reviewed and evaluated the historical development of sake in Japan in general [1]. Here, we focused on organic aspect. Unlike wines, the production of organic sake has not played a major role. We analyzed the current status of the industry and what was underpinning challenges for organic sake, mainly from production perspectives, focusing on different procurement strategies by four brewers.

By doing so, this study explored how possible it was for Japanese sake of organic rice to increase its production as well as organic rice production. For this purpose, this study examined what sake breweries conducted to initiate and developed its organic sake production and sale. This study first described the current status of organic sake production. Second, this study described and analyzed the procurement of organic rice by the breweries. Third, the study described the sales and exports of organic sake. By analyzing the procurement of organic

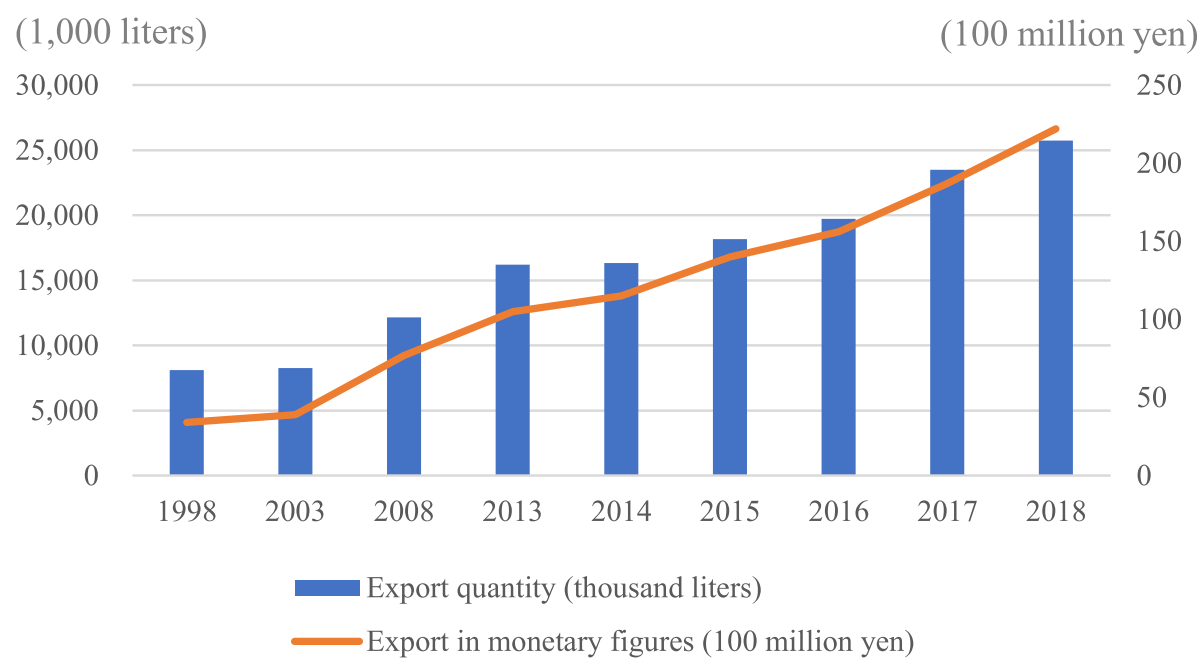

Fig. 2 Export of sake from Japan. From 1998 to 2018, the export of sake steadily increased both by quantity and monetary value. The increase was $318 \%$ by quantity and $653 \%$ by monetary value. The main type of sake for export is premium sake. As organic sake is in this category, more of it is expected to export. Source: [4] 


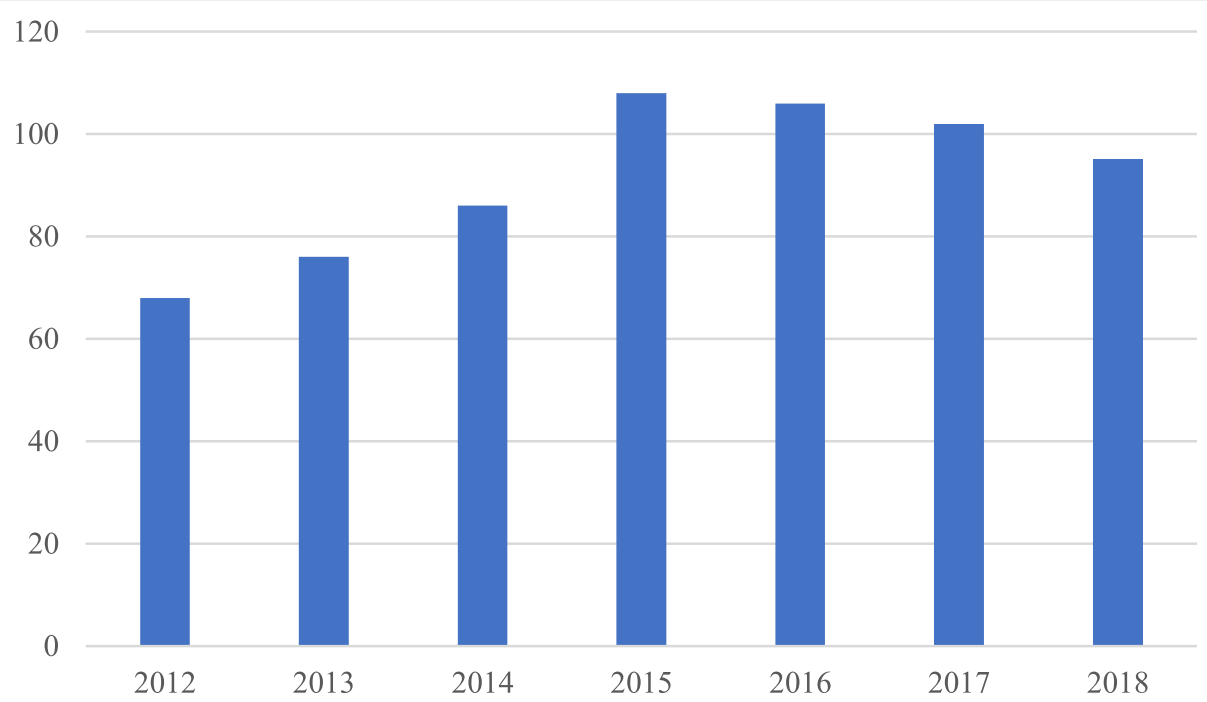

Fig. 3 Production of sake-brewing rice (100 tons). The production of sake-brewing rice increased until 2015, and then it decreases. The overproduction is followed by the decrease of the production [4]. Higher price of sake-brewing rice was attractive for the farmers. In 2018, the price of conventional edible rice and that of sake-brewing Yamadanishiki variety in Hyōgo Prefecture was 14,524 yen/60 kg and 23,600 yen/60 kg, respectively. To avoid the overproduction, MAFF recommends the farmers to be sensitive to the market information. Sources: $[4,6]$

rice, they initially procured rice locally, in order to emphasize the bonding with terroir, local agriculture and environment. Availability and affordable price became a bottleneck. Faced with a lack of local supply of organic rice when increasing the productions, Brewery D in central Japan had to think of different product strategies.
Simultaneously, the increase of organic rice price could pressure breweries to raise the prices of organic sake or demand the arrangement with local organic farmers for the long-term relations with the discounted rice prices. As such, it is implied that affordable price and secure supplies are bottleneck to promote the production of

Table 2 The basic data on the breweries to produce organic sake. They are small to medium-sized breweries and located in different regions. They are rather veteran breweries to produce organic sake with the experiences of about 10 to 20 years. Despite this, the ratios of organic sake to total is small for the four breweries. Though one brewery produces organic rice for itself, the others buy from a small number of farms. The breweries can sell organic sake as organic without a JAS certificate in Japan. They are requested legally to comply with the Organic Labelling Standards of Sake among Others of National Tax Agency [14]

\begin{tabular}{|c|c|c|c|c|}
\hline & Brewery A & Brewery B & Brewery C & Brewery D \\
\hline Brewery location & Tōhoku & Hokuriku & Chūgoku & Chūbu \\
\hline Year of company creation & 1973 & Sometime in 1818-1831 & 1867 & 1738 \\
\hline Year of incorporation & 1973 & 1950 & 1952 & 1970s \\
\hline Capital fund & 150 million yen & 51 million yen & 10 million yen & 214 million yen \\
\hline No. of employees & About 140 & 19 & 9 & 17 \\
\hline No. of non-regular or part-time employees & About 40 & About 10 & 4 & 3 \\
\hline Annual sake production & $2343 \mathrm{kl}$ & $252 \mathrm{kl}$ & $180 \mathrm{kl}$ & $450 \mathrm{kl}$ \\
\hline Annual brewing capacity & $5400 \mathrm{kl}$ & $540 \mathrm{kl}$ & $360 \mathrm{kl}$ & $900 \mathrm{kl}$ \\
\hline Average rice-polishing ratio & 60 to $65 \%$ & 67 to $68 \%$ & $60 \%$ & $68 \%$ \\
\hline Year to start organic sake production & 2002 & About 2011 & 2007 & About 2000 \\
\hline Annual production of organic sake & $42 \mathrm{kl}$ & $4.3 \mathrm{kl}$ & About $3.1 \mathrm{kl}$ & $36 \mathrm{kl}$ \\
\hline The ratio of organic sake to annual production (\%) & $1.8 \%$ & $1.7 \%$ & $0.9 \%$ & $8.0 \%$ \\
\hline Average polishing ratio of organic rice & $60 \%$ & $70 \%$ & $70 \%$ & 62 to $63 \%$ \\
\hline The amount of organic rice to purchase & $32,160 \mathrm{~kg}$ & $3600 \mathrm{~kg}$ & $2800 \mathrm{~kg}$ & \\
\hline No. of supplying organic rice producers & 4 or 5 & 1 & Self-supply & 4 \\
\hline Organic certification in a brewery & & JONA, EU, COR & JAS, EU, USDA & \\
\hline
\end{tabular}


organic sake, similar to challenges facing most of the organic agriculture and processed foods [13].

\section{Data collection method}

This study derived from the questionnaire survey of four sake breweries conducted in January and February 2020 (Table 2). These breweries produced sake from JAS certified organic rice. JAS certification is the only existing legal organic certification in Japan. The intensive Internet search resulted in the identification of roughly 31 breweries using organic rice. We captured varieties in the locations and pricings by focusing on four breweries. These differences led to the diverse branding and sales strategies. The questionnaire asked them about their corporation, entire sake-brewing, organic sake-brewing, organic-sake sales, and prospects, difficulties, and policies (Appendix). The authors asked the questions by phone (interviewing a president of one brewery), by email (with a staff member of one brewery), and on site (one brewery to interview a chairperson and a chief brewer) (Figs. 4 and 5). The authors additionally visited one of the breweries in site and enquired the

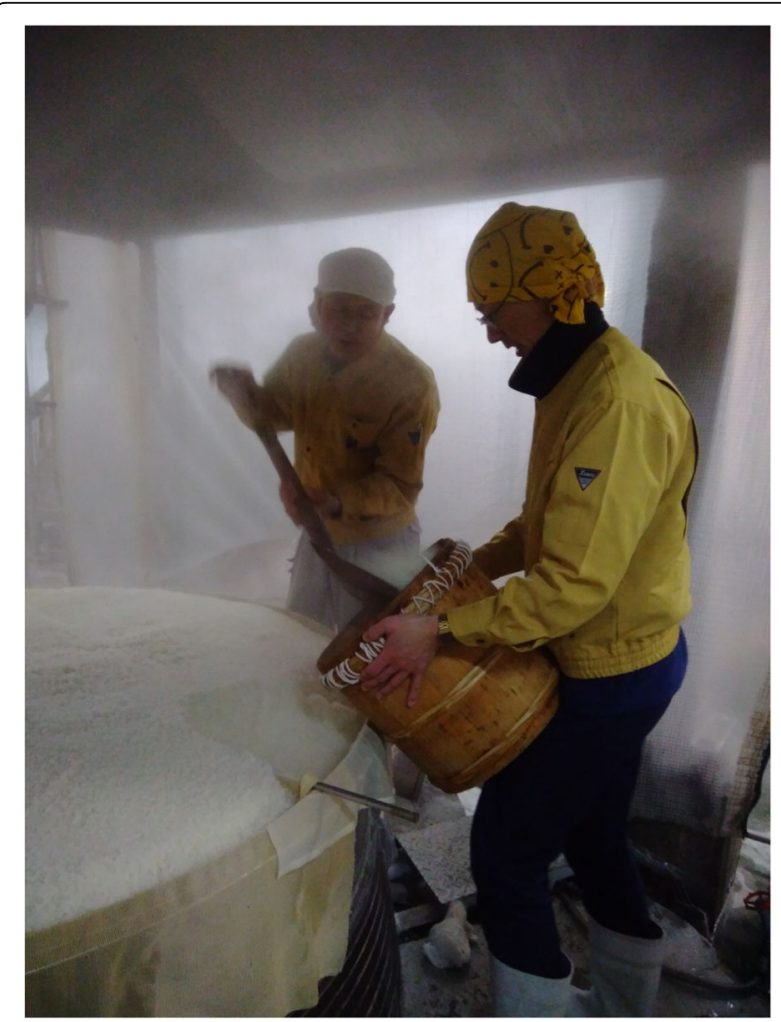

Fig. 4 Steamed rice dug to be cooled and malted. In sake-brewing, rice is used in the three processes. For malt making, steamed rice is mixed with koji mold [15]. For making yeast mash, rice and malt are mixed with lactic acid, water, and yeasts. Enzymes from malt turn rice into sugar. This increases yeasts. In shikomi, rice and malt are added to yeast mash for further fermentation. Note. Conventional rice was steamed on the day of the visit. Photo by authors

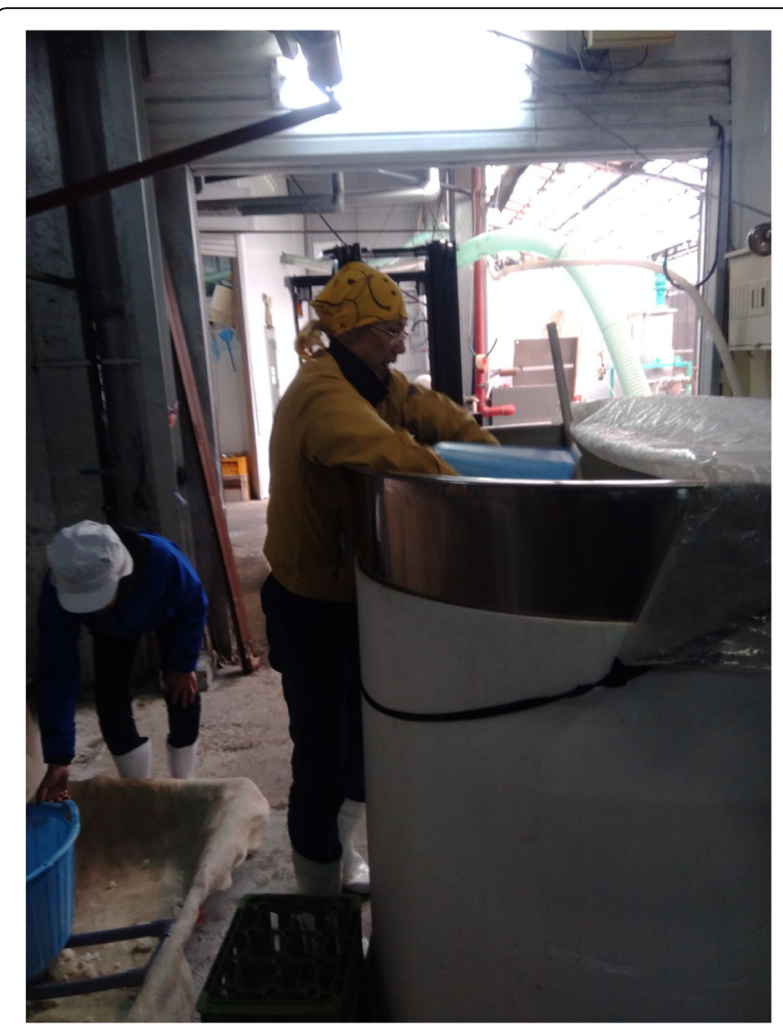

Fig. 5 Steamed and cooled rice was added to unrefined sake. In shikomi, rice and malt are added to yeast mash for further fermentation [15]. To sustain the activeness of the yeasts, rice and malt are not added once but three separate times. One third of the total amount is put each time. Rice is cooled by a machine before being put into a tank. All rice including spilled one is collected during the process. Note. Conventional rice was steamed on the day of the visit. Photo by authors

supplementary questions after they asked the questions by phone.

\section{Results}

Brewery characteristics and organic sake production

The four breweries in this study in focus varied in their sizes, from regional to local ones with production amount of 180 to $2343 \mathrm{kl}$ or employees from nine to about 140 (Table 2). In general, they were small to medium sizes. For comparison, Hakutsuru, the largest sake brewing company in Japan, produced $61,100 \mathrm{kl}$ in 2011 and currently hired 432 regular employees in 2019 $[16,17]$.

For the background knowledge, Brewery D experienced a corporate takeover three years ago and became part of a large and transnational food and restaurant group based in Japan.

The production of organic sake currently plays a minor role in the breweries' entire production. These breweries started organic sake production 13 to about 20 years ago. The ratios of organic sake production in 
overall production amount occupy 0.3 to $1.8 \%$ in the four cases. Their productions ranged from about 0.5 to $42 \mathrm{kl}$. They required 2800 to $32,160 \mathrm{~kg}$ of organic rice and contract with up to 5 producers. Brewery $\mathrm{C}$ is the only one to produce organic rice for itself. The other breweries contract with organic rice farmers.

Breweries of organic certifications sake are requested legally to comply with the Organic Labelling Standards of Sake among Others of National Tax Agency [14]. Unlike agricultural products, they do not need to be certified under the Organic JAS Standards of MAFF (the ingredients of rice need to comply with JAS as they are agricultural products with the legal framework of MAFFs). When exporting organic sake, they need to follow organic standards of importing countries and get the necessary certifications. For such purpose, the breweries ask a qualified audit company to check their facilities and practices for both domestic and foreign certifications. Breweries B and D went through this process to obtain the foreign certifications such as EU, USDA, and COR (Canadian standards) in addition to domestic ones like JAS and JONA (Japan Organic \& Natural Foods Association) [Brewery B president, personal communication, January 31, 2020; Brewery C president, personal communication, January 27, 2020]. JONA is a nonprofit organization and an IFOAM (International Federation of Organic Agriculture Movements) member to certify organic agriculture and food though JONA certification cannot claim organic to sell inside Japan.

\section{Reasons to initiate organic sake production}

All four breweries, including the one producing rice for itself, mentioned the connections with local farmers and expressed their willingness to brew with local rice when they first initiated the production with organic ingredients. The two breweries recognized that local organic rice farmers existed and expressed desire to stabilize their rice production and sale [Brewery B president, personal communication, January 31, 2020; Brewery D chairperson, personal communication, February 10, 2020]. They wanted to help these ambitious organic rice farmers. As well, Brewery D thought it could contribute to local community development through sake. The chairperson of Brewery D said, "If everyone plays a role, this is a good 'sprout' for the public campaign by the city." By pursuing organic sake in depth, Brewery B was reminded of the basic components of sake brewing, returning to the local origin and environment. He decided to return to the origin and brew sake in an old way: brewing sake from rice made by local farmers on the local land. Organic sake would embody the origin. He thought that this could be a way to overcome the sluggish situation in the industry.
The two other breweries tried to produce differentiated sake for sale [Brewery A staff, personal communication, January 24, 2020; Brewery C president, personal communication, January 27, 2020]. Brewery A organized a group of local farmers to study rice for sake production 7 years before starting the production of organic pure-rice daiginjō-shu. Brewery $\mathrm{C}$ exported sake and found, "Western countries evaluate organic per se. We produce rice ourselves for thirty years. We can differentiate sake more by brewing with organic rice" [Brewery C president]

\section{Production and certifications}

The productions of sake with organic rice for all four producers were not faced with technical difficulties contrary to the initial expectations. They used exactly the same instruments with similar procedures. Yet, it was critical to separate ingredients and other processes to manage the chain-of-custody. The mainstream productions were brewed with conventional rice, and the breweries were supposed to wash all the instruments including barrels and filter cloth before brewing organic rice [Brewery $\mathrm{B}$ president, personal communication, February 6, 2020; Chief brewer in Brewery D, personal communication, February 10, 2020]. Furthermore, certified rice mills were available in the same or adjacent prefectures [Brewery B president; Chief brewer in Brewery D].

In order to be certified for export, Brewery $C$ got certified under JAS, EU, and USDA [Brewery C president, personal communication, January 27, 2020]. As this brewery produced rice for itself, it had both its farm and brewery certified. This burdened the production as all certifications costed roughly $10 \%$ or less of the sales from organic sake. Brewery D does not have a certification [Chief brewer in Brewery D, personal communication, February 10, 2020]. To export its sake, documents were added to prove that rice came from the prefectures with a negligible level of radiation.

\section{Organic rice procurement}

Majority of breweries contracted the amount and price of the organic rice in advance with the farmers before the seasons of rice productions (the so-called contract basis production). The only exception was Brewery $\mathrm{C}$ producing all necessary organic rice for productions. As for the rice varieties, Brewery $\mathrm{C}$ only handled Yamadanishiki, sake-brewing rice, as organic rice [Brewery $\mathrm{C}$ president, personal communication, January 27, 2020]. Breweries $\mathrm{A}$ and $\mathrm{D}$ bought both organic sake-brewing and organic edible rice [Brewery A staff, personal communication, February 3, 2020; Brewery D chairperson, personal communication, February 10, 2020]. Brewery B exclusively handled organic edible rice [Brewery B 
president, personal communication, January 31, 2020]. This initially reflected the situation of the farmer side before.

Before, we exclusively bought Gohyakumangoku [sake-brewing rice]. The production of organic Gohyakumangoku was unstable between bad and good years. We asked the farmer to produce and sell organic edible rice. He can sell it somewhere else [in a good year]. [Brewery B president]

Brewery B only had one farmer to purchase organic rice. Before, if the farmer produced less sake-brewing rice than Brewery B demanded in a bad harvesting year, the brewery changed the production plan adaptively. To avoid such shortage, farmers produced more than the requested amount, yet in this case, there are two risks for good harvest years; either farmers had to sell rice to nonlocal breweries, or Brewery B would need to purchase excessive amount. To avoid risks on both ends, the farmer and the brewery decided the procurement of organic edible rice in advance. By doing so, the farmer secured production more than the brewery needed, and the rest were sold directly to the consumers. By having this channel of direct sales, the brewery could avoid the risk of the unstable productions and procure the stable supply of organic rice for brewing. Consequently, Brewery $\mathrm{B}$ abandoned the idea of brewing sake with organic sake-brewing rice. For the organic edible rice, Brewery $\mathrm{B}$ paid about 50\% higher than conventional edible rice (Fig. 6). Brewery B explained that the price was lower than those of farmer's organic edible rice and reputed conventional Yamadanishiki, but was higher than other kinds of sake-brewing rice. Currently, a farmer offered discount price to the brewery because they had a long trading partnership. This still kept the contract price to observe organic premium as both edible and sake-brewing rice.

Regarding contract price, the chairperson of Brewery D mentioned that their price was higher than cheap Yamadanishiki [personal communication, February 10, 2020]. To illustrate in Fig. 6, it could be between 14,524 yen and 23,600 yen which is the price of Yamadanishiki from Hyogo, supposedly the most expensive sake-brewing rice. To ascertain the quality of rice, Brewery A added the incentive [Brewery A staff, personal communication, February 3, 2020]. The brewery checked the indicators of rice quality such as a crack and the weight of one thousand grains. With better quality, the brewery paid about 500 to 1500 yen per $60 \mathrm{~kg}$.

With such price range, did it expand rice production for sake? Though Brewery $\mathrm{C}$ produced its own organic

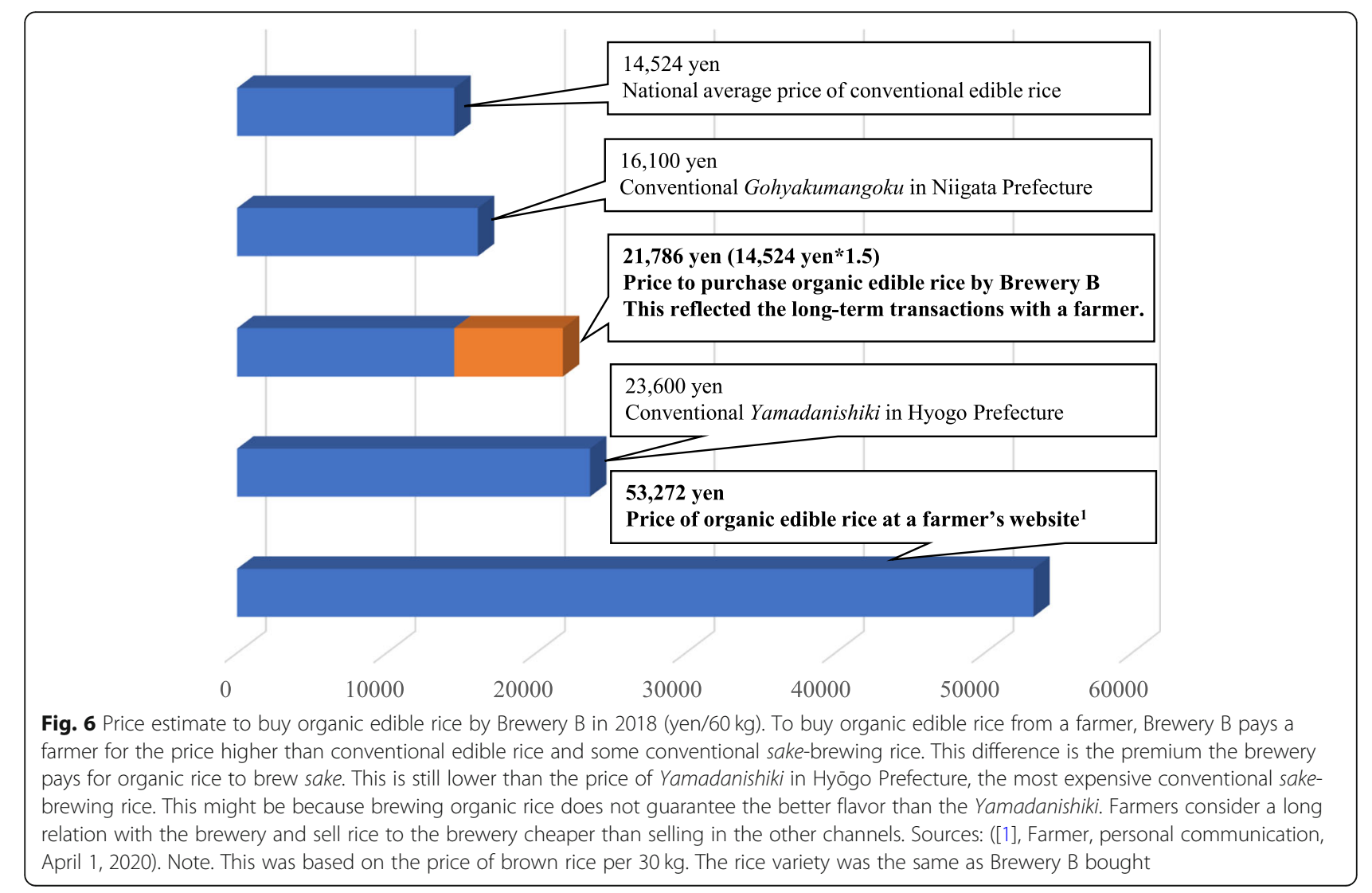


rice for about 15 years, it decreased the production of organic rice owing to the increase of weeding [Brewery C president, personal communication, January 27, 2020]. Employees of Brewery $\mathrm{C}$ worked in the rice fields of 18 ha including 1.8 ha of the ones for organic Yamadanishiki. They used a weeding machine and weeded by hand afterwards as annual work. Furthermore, Brewery A was cautious about the rapid expansion of organic rice for sake. Brewery A staff said, "Organic does not mean high quality rice. Farmers who know how to produce high quality rice get to be organic" [personal communication, February 3, 2020]. Therefore, it was not very easy to find rice farmers who would become organic and own the skills to endure the risk of production decrease with conversion and harvest high-quality organic rice for sake-brewing.

To increase the supply of organic rice, Breweries A and $\mathrm{C}$ added contract organic farmers. Brewery A contracted with a farmer in the local farmer group and then asked a local nonprofit certifying organization of organic agriculture and found additional farmers inside the prefecture [Brewery A staff, personal communication, February 3, 2020]. This allowed 99\% of their procurement of conventional and organic rice to be local. Besides, Brewery D asked its corporate group to find farms [Brewery D chairperson, personal communication, February 10, 2020]. This enabled the brewery to contract with the farmers far away in western Japan. With the introduction of nonlocal organic rice, Brewery D diversified its products. It separated the products by local or nonlocal and diversified the sake from nonlocal rice by rice variety. It further attached familiar animals such as a cat, a dog, and a rabbit in the product names and labels of sake from each variety of nonlocal organic rice.

\section{Domestic sales and exports}

Organic sake was not sold well in a local area. Instead, it could be sold in "various places" [Brewery C president, personal communication, January 27, 2020]. It was sold in shops and Teikei groups specialized in organic food [Brewery D chairperson, personal communication, February 10, 2020]. Teikei is a group of organic farmers and consumers to facilitate the productions and sales of organic agricultural products [18]. Supermarkets were able to sell organic sake while they explained the quality through stories [Brewery B president, personal communication, January 31, 2020]. For Brewery B, organic sake was not sold well because its price was high. The taste was too unique for the general population especially because Brewery B did not use sake-brewing rice. One exception to sell organic sake was a souvenir shop to connect sake with the locality of agriculture and sake brewing.
Brewery A limited its sale domestically and kept the character of the product in the domestic niche market [Brewery A staff, personal communication, January 24, 2020]. On the other hand, all the other breweries exported their organic sake to foreign countries and places such as EU, the USA, Vietnam, China, and Hong Kong. They sold the sake to alcohol traders and Japanese food companies [Brewery $\mathrm{C}$ president, personal communication, January 27, 2020]. To find sale channels, they went to trade fairs [Brewery $\mathrm{B}$ president, personal communication, January 31, 2020]. Brewery C first sold organic sake in EU through a trader who was known by transactions in the past.

In the process of exporting organic sake, Breweries B and $\mathrm{C}$ said they had difficulty in finding regular customers or repeaters [Brewery B president, personal communication, January 31, 2020; Brewery C president, personal communication, January 27, 2020]. Once they made a deal with a foreign wholesaler, the sale would generally increase. However, it normally slowed down in case of organic sake. Both Brewery B and C attributed the decline to high prices of organic sake. Brewery C raised the price to absorb the high cost for the production including the certifications; otherwise, their sales would be limited to certain countries [Brewery B president]. Furthermore, Brewery B thought they had to compete with local alcoholic beverages including wines in Europe. Similar to the situation in exports, high price prevented repeated sales in Japan. Organic sake had to compete with conventional sake. Japanese consumers did not value organic compared to foreign consumers. Brewery $\mathrm{B}$ expressed the difficulties with organic sake. Brewery B is undecided whether they would halt brewing organic sake and keep selling a stock in the brewing season of 2020 to 2021.

\section{Discussion}

We illustrated the processes for Japanese breweries to produce and sell sake made from certified organic rice in the introduction. The result serves as basis to increase organic agriculture in Japan, including future export strategy (Fig. 7). To start the production of organic sake about 10 to 20 years ago, all breweries in this study were interested in rice farming in the region. Then, availability of local organic rice affected the product strategies. Certain breweries found the sale increased and had to find additional rice farmers. The breweries such as Brewery $\mathrm{D}$ could not find organic rice farmers in a local area, and they found the ones away from their own locations [Brewery D chairperson, personal communication, February 10, 2020]. They could start the products to reflect the reality of farmers' distant locations and invent new product identities. Conversely, they lost the strong local bond to insist on locality, terroir $[1,19]$. Local 


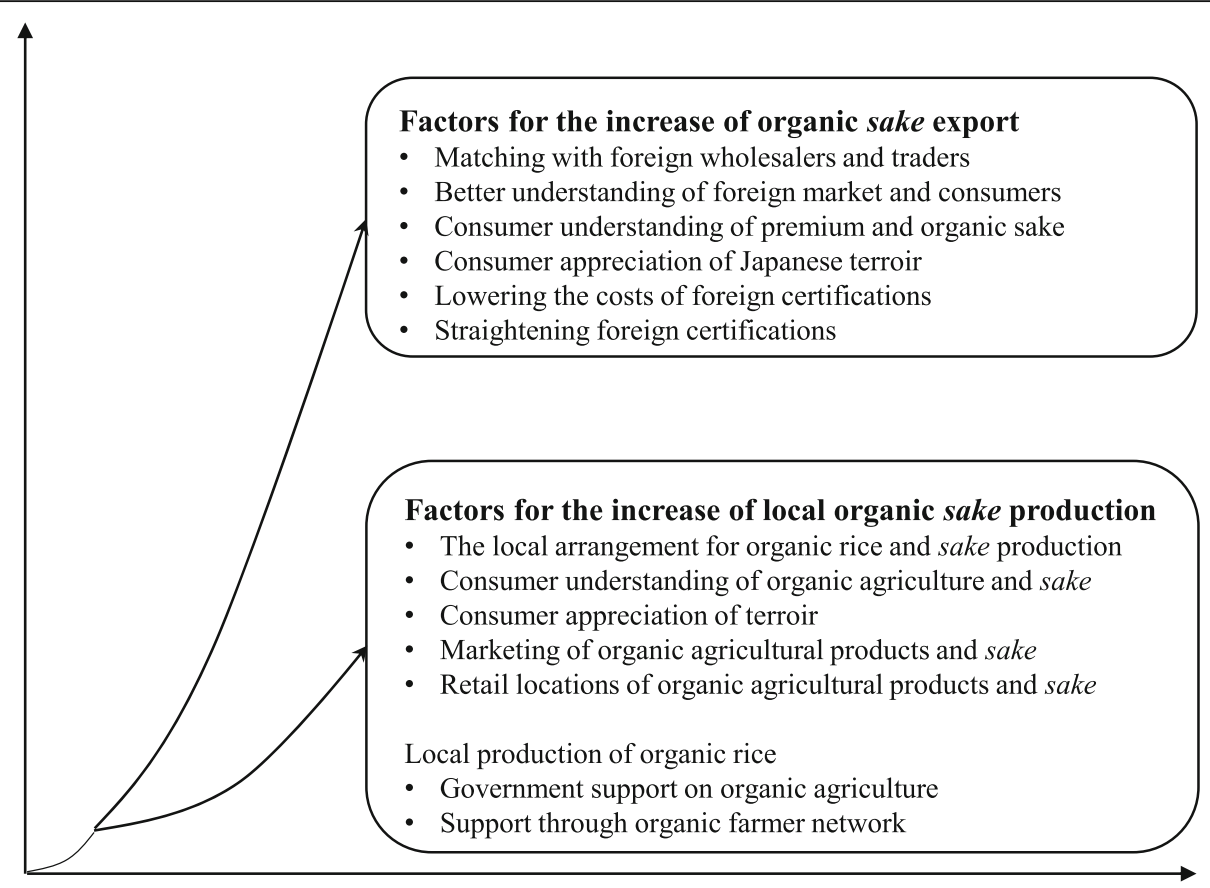

Fig. 7 Factors to increase local organic rice and sake production and export. To increase the export of organic sake, the brewers need to know the market condition and find the stable matches with foreign wholesalers and traders. The recognition by consumers needs to consist of the two types: one for sake and the other for organic. This also applies to the increase of the local demand for organic sake. Whether local organic rice is available or not can change the marketing and sales strategies of organic sake. The government policy would increase organic rice at a local level

agriculture missed the sale opportunity of organic rice. Even at an incremental pace, organic rice farmers would increase to supply rice for breweries. The support by local and national governments and existent organic farmers could help avoid this opportunity costs [20,21].

The result section discussed the price of organic rice for sake. This section answered the questions raised in the introduction; whether another sake category of organic sake help stabilize the production of sake and sake-brewing rice or not. We further examined what it means for exporting makers in the introduction. In short, organic sake played a marginal role in economic sense, contributing less as profit. Yet, it served as catalysis to change the contract relationships and brought the brewers, rice producers to basic principles, contributing to reflexivity of the producers. Organic rice price affected breweries to decide the prices of organic sake or demand the arrangement with local organic farmers for the long-term relations. For Brewery B, it was 50\% more than the price of conventional edible rice [Brewery $B$ president, personal communication, January 31, 2020]; for Brewery D, it was about the same as those of low-tomiddle quality sake-brewing rice [Brewery D chairperson, personal communication, February 10, 2020]. The procurement price of organic rice could reflect the competitiveness of organic sake in the current market. Organic sake had difficulty in competing with conventional high-quality sake in Japan and wine especially in the European market. To perform well in both markets, organic sake needed to prove its quality and premium. Furthermore, in the case of Brewery B, as a rice farmer got the reputation and premium, the price got more expensive than to sell the brewery [Brewery B president, personal communication, February 6, 2020]. If the price of organic rice increased, the breweries would have more difficulty in buying and brewing organic rice. Thus, this study implied the possibility to stagnate the production of processed organic food owing to a further price increase of organic ingredients. Some differentiation in price premium could exist by product [22]. Without the concurrent additions of premium, the processed food or drinks might not be the strategy for the development of local organic agriculture. In the case of this study, a brewery and a farmer regarded the experience of long-term transactions and agreed to the price assuming the future transactions. Like this, the breweries could devise the strategies to align the production of organic sake in line with the enhancement of its competitiveness through terroir [1, 19, 23, 24]. This could make the local breweries of organic sake gain some edge against national and transnational breweries. In return, this would be how organic rice farmers would have a chance to keep a stable market channel at a local level. 
Besides, the strategies would be suggested to promote both inputs and processed products as organic so that consumers could realize the premium of them (Miyake Y, Uchiyama Y, Kohsaka R: Status and trends of urban organic agricultural policy in Japan: the survey on ordinance designated cities, forthcoming). For this purpose, the understandings of both domestic and foreign consumers would be necessary; for example, organic sake needs some regular place to sell. Owing to higher price, it could not keep repeaters and lose the place to sell. Reversely as a marketing trial, providing organic sake with some regular spots would give the chance of consumers to be familiar with the products [25]. Additionally, selling with other organic sake or other organic products, the shops and supermarkets could stimulate the interests of the consumers and familiarize them with organic foods including sake.

This study analyzed the current situation of organic sake production through the interviews of rare organic sake breweries in Japan. This study focused on sake and rice and showed the reality of competition involving both inputs and processed products. This study provides the implication for expansion of organic sake-brewing and rice for sake as well as implications for the development of organic agriculture involving organic processed food. To maintain the competitiveness and image of high-quality organic processed food, the relation between ingredients and processed products should firmly be taken into consideration for the productions and sales and local organic agriculture. This study showed availability and affordability of ingredient organic products were a key. The mismatch could affect the product identities. Furthermore, maintaining the sales would demand consumer understandings of organic agriculture in general as well as specific products. While studying future productions, sales, and exports of sake, more ideas and studies are necessary for the promotion of organic processed products to develop local organic agriculture in other places in Asia. As is the case with Japan, the connection of organic and local was traditional but new to explore.

\section{Appendix}

Questions to ask organic-sake breweries in this study

\section{General questions on a corporation}

Brewery location

Year of company creation

Year of incorporation

Capital fund

\# of employees

\# of non-regular or part-time employees

General questions on sake-brewing

Annual sake production

\section{Appendix (Continued)}

Annual sale

Annual brewing capacity

Average rice-polishing ratio

Questions on organic sake-brewing

Year to start organic sake production

Annual production of organic sake

Average polishing ration of organic rice

Reasons to start organic sake production

Methods to start organic sake production

Questions on organic-rice purchase

The amount of organic rice to purchase

How to decide the prices of organic rice

\# of supplying organic rice producers

Farm size of supplying organic rice producers

How to find organic rice producers

How much care on local purchase of organic rice

Other special measures to buy organic rice

Questions on organic-sake sales

Annual sale of organic sake

How to find the purchasers of organic sake

How much care on local consumption of organic sake

How is organic sake exported?

\section{Questions on prospects, difficulties, and policies}

Any prospect to increase organic sake production

Any difficulty in organic sake production

Any policy measures to apply

Authors' contributions

Yoshitaka Miyake and Ryo Kohsaka coauthored the manuscript. The authors read and approved the final manuscript.

\section{Funding}

The study for this article was funded by Policy Research Institute, MAFF of Japan as the Commissioned Project on the Policy Science of Agriculture, Forestry, and Fisheries from the year 2018 to 2020: Factors to Facilitate Production and Export of Organic Agricultural Products: Analysis of Status and Trends in EU and Implications for Japan. In addition, the study was funded by the JSPS KAKENHI Grant Numbers JP16KK0053 and JP17K02105 and DAIKO Foundation.

Availability of data and materials

The data of this study are available upon request.

Competing interests

The authors declare no conflicts of interest.

Received: 7 April 2020 Accepted: 4 August 2020

Published online: 03 September 2020

\section{References}

1. Sato J, Kohsaka R. Japanese sake and evolution of technology: a comparative view with wine and its implications for regional branding and tourism. J Ethn Foods. 2017;4(2):88-93. 
2. Aramasa. History. n.d. http://www.aramasa.jp/around/. Accessed 27 July 2020 [in Japanese].

3. Kohsaka R, Matagi S, Sato J, and Uchiyama Y. 6th sector industrialization through the perspective of Japanese-sake ingredients: the cases from Hokuriku and Tōhoku. In: The Venture Business Institute at Otemon Gakuin University, editor: Agriculture of people and mechanism: 6th industrialization to pass a region from people to people. Ibaraki, Ōsaka. Otemon Gakuin University Shuppan; 2016. p. 95-126. [in Japanese].

4. Ministry of Agriculture, Forestry, and Fisheries. The situation of Japanese sake. 2019. https://www.maff.go.jp/j/seisaku_tokatu/kikaku/attach/pdf/sake-3. pdf. Accessed 20 Jan 2020. [in Japanese].

5. Sankei Shimbun. New entries will be permitted for brewing sake. specified for export. The Government will Amend Liquor Tax Law. 2019. https://www. sankei.com/economy/news/191120/ecn1911200019-n1.html. Accessed 31 Mar 2020. [in Japanese].

6. Ministry of Agriculture, Forestry, and Fisheries. The summary of the results from the situation involving material rice for Japanese sake and the amount of the demand for rice preferable for sake brewing. n.d. https://www.maff. go.jp/j/seisan/keikaku/soukatu/attach/pdf/161104-2.pdf. Accessed 20 Jan 2020. [in Japanese].

7. Miyake Y, Kohsaka R. From hoes to story-telling as "Weapons of the Weak": farmers' resistance to neoliberal 2007 Multi-Product Management Stabilization Plan in Japan. J Ethn Foods. 2020;7(1):1-9.

8. Support Organization to Secure the Stable Supply of Rice Grain. The change of annual weighted average prices of successful bids on all varieties (index price). n.d. https://www.komenet.jp/torihiki/02/01/01.pdf. Accessed 22 Jan 2020. [in Japanese].

9. Ministry of Agriculture, Forestry, and Fisheries. The change of bilateral-bidding prices (2009-2018). n.d. https://www.maff.go.jp/j/council/seisaku/syokuryo/1 81128/attach/pdf/re_data_3-2.pdf. Accessed 22 Jan 2020. [in Japanese].

10. Baumert N. Les métiers du saké : vers un retour aux sources? In: Gadea C, Olivesi S, editors. Les métiers de la vigne et du vin. Grenoble: Presses Universitaires de Grenoble; 2019. p. 69-88.

11. Iga M. Collaborative relation among Japanese sake breweries and producers of sake-brewing rice in the supply system of Japanese sake. Chirigaku Hyöron. 2008:81(4):150-78 [in Japanese].

12. Kajima S, Tanaka Y, Uchiyama Y. Japanese sake and tea as place-based products: a comparison of regional certifications of globally important agricultural heritage systems, geopark, biosphere reserves, and geographical indication at product level certification. J Ethn Foods. 2017:4(2):80-7.

13. Miyake $Y$, Kohsaka R. History, ethnicity, and policy analysis of organic farming in Japan: when "nature" was detached from organic. J Ethn Foods. 2020;7(1):1-8.

14. National Tax Agency. Organic labelling standards of sake among others. 2000. [in Japanese].

15. Masumi. The processes to brew Masumi. n.d. https://www.masumi.co.jp/ spirit\#process. Accessed $27 \mathrm{Jul} 2020$ [in Japanese].

16. Narita, T. Hakutsuru n.d. Sake expert. n.d. http://sakeexpert.com/jfc_sake_pro/ hakutsuru/. Accessed 23 Mar 2020. [in Japanese].

17. Hakutsuru Sake Brewing Co. About Hakutsuru. 2019. http://www.hakutsuru. co.jp/english/company/about.html. Accessed 23 Mar 2020.

18. Hatano T, Fujimoto T. Connecting food and agriculture at a local level-the trial called organic agricultural movements. In: Akitsu M, Sato Y, Takenouchi H, editors. New ethics on food and agriculture. Kyoto: Shōwadō. p. 47-70. [in Japanese].

19. Saito O. Deepening the collaboration among agriculture, commerce, and industry, and value chains. In: Kashiwa M, editor. Logics of regional renovations and actor formations: new trials in agriculture and rural communities. Tokyo: Waseda Daigaku Shuppankai; 2019. [in Japanese].

20. Kohsaka R, Matsuoka H. Analysis of Japanese municipalities with Geopark, $M A B$, and GIAHS certification: quantitative approach to official records with text-mining methods. SAGE Open. 2015;5(4):2158244015617517.

21. Tashiro A, Uchiyama Y, Kohsaka R. Impact of Geographical Indication schemes on traditional knowledge in changing agricultural landscapes: an empirical analysis from Japan. J Rural Stud. 2019;68:46-53.

22. Michelsen J, Hamm U, Wynen E, Roth E. The European market for organic products: growth and development. Stuttgart Hohenheim: Universität Hohenheim; 1999.

23. Kohsaka R. The myth of washoku: a twisted discourse on the "uniqueness" of national food heritages. J Eth Foods. 2017;4(2):66-71.
24. Kohsaka R, Matsuoka H, Uchiyama Y. Capturing the relationships between local foods and residents: a case in the Noto region, Japan. J Ethn Foods. 2016;3(2):86-92.

25. Uchiyama Y, Fujihira Y, Matsuoka H, Kohsaka R. Tradition and Japanese vegetables: history, locality, geography, and discursive ambiguity. J Ethn Foods. 2017;4(3):198-203.

\section{Publisher's Note}

Springer Nature remains neutral with regard to jurisdictional claims in published maps and institutional affiliations.

\section{Ready to submit your research? Choose BMC and benefit from:}

- fast, convenient online submission

- thorough peer review by experienced researchers in your field

- rapid publication on acceptance

- support for research data, including large and complex data types

- gold Open Access which fosters wider collaboration and increased citations

- maximum visibility for your research: over $100 \mathrm{M}$ website views per year

At BMC, research is always in progress.

Learn more biomedcentral.com/submissions 